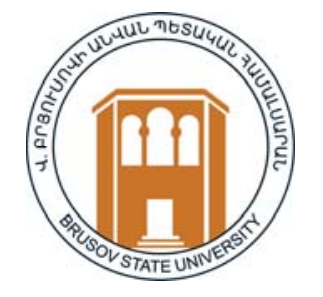

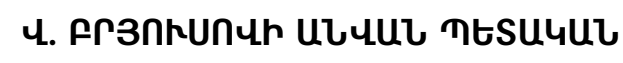
CUUULUURUL

ГОСУДАРСТВЕННЫЙ УНИВЕРСИТЕТ

ИМЕНИ В. БРЮСОВА

BRUSOV STATE UNIVERSITY

คulคtr

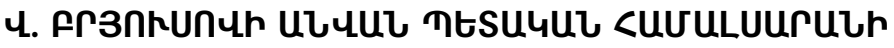
ВЕСТНИК ГОСУДАРСТВЕННОГО УНИВЕРСИТЕТА ИМЕНИ

B. БРЮСОВА

BULLETIN OF BRUSOV STATE UNIVERSITY

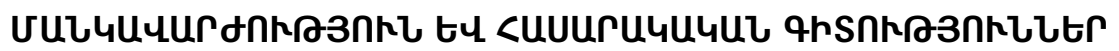

ПЕДАГОГИКА И СОЦИАЛЬНЫЕ НАУКИ

PEDAGOGY AND SOCIAL SCIENCES

2(55)

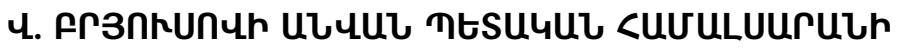

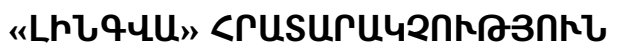

เГヒบuし - 2021 
<S7 37.013

DOI: 10.51307/182931072015233260/21.2-54

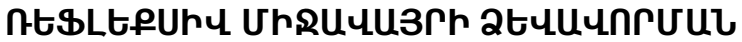

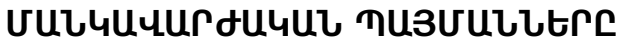

\section{ఒurhఒt uUshし3u孔}

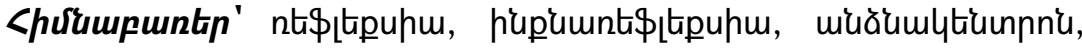

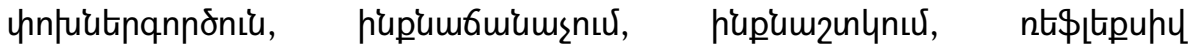

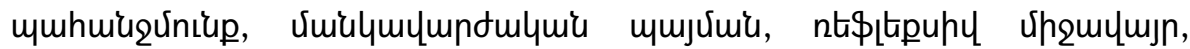

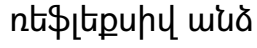

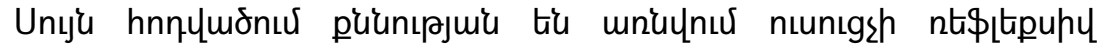

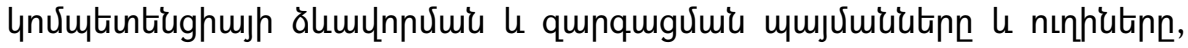

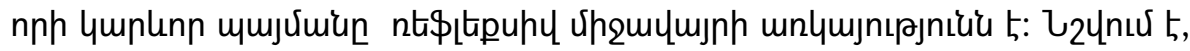

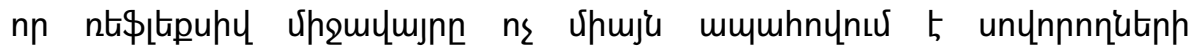

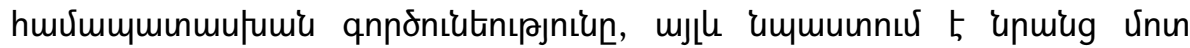

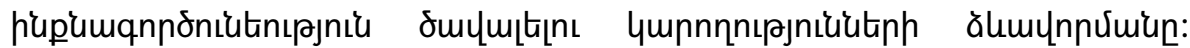

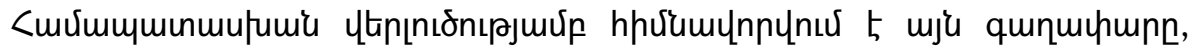

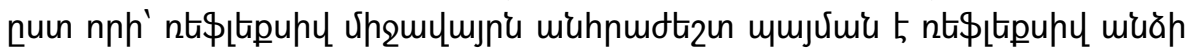

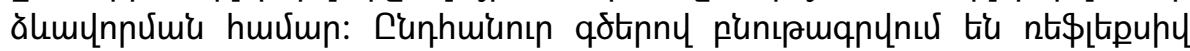

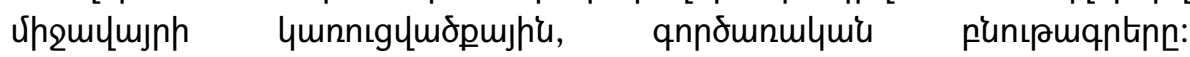

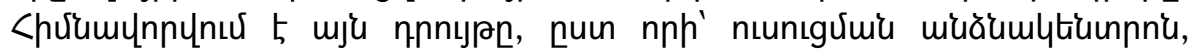

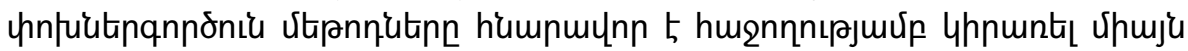

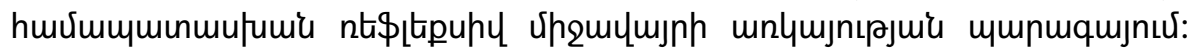

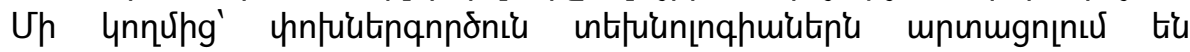

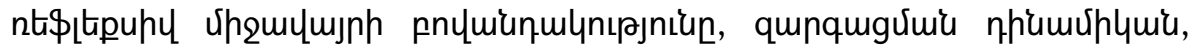

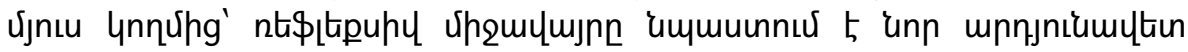

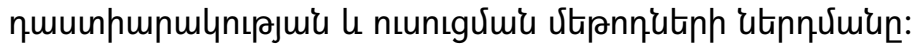

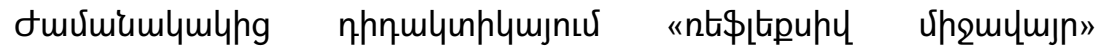

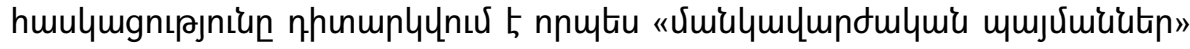

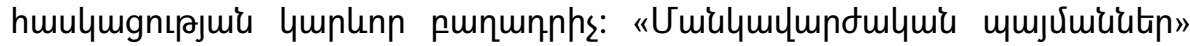

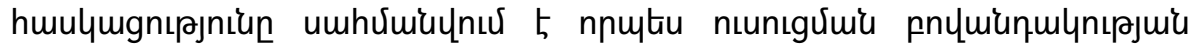

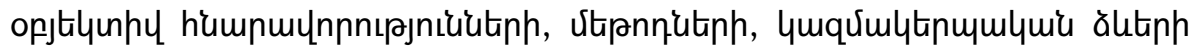

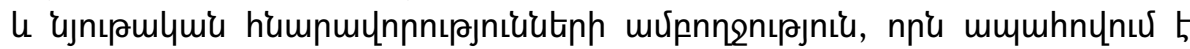

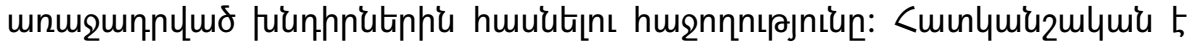

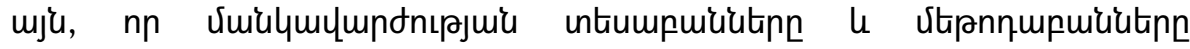




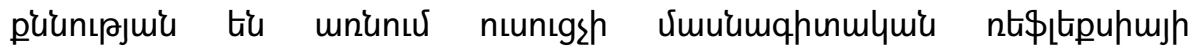

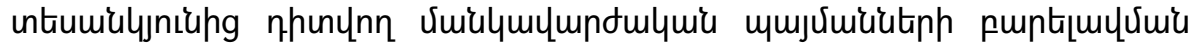

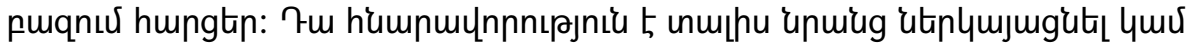

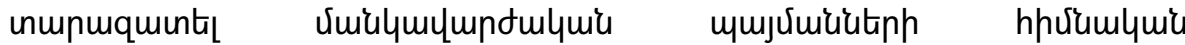

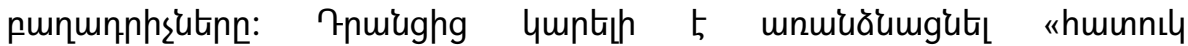

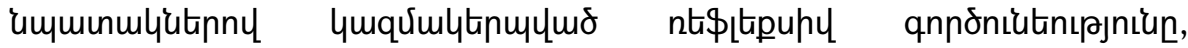

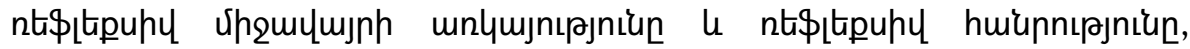

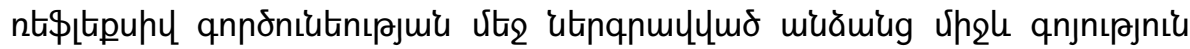

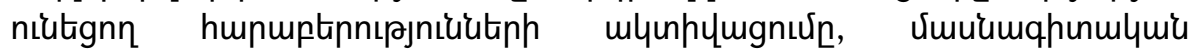

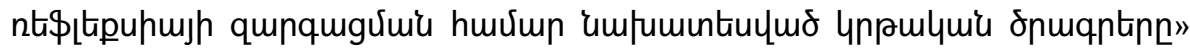
(Аверина 2011: 72-77):

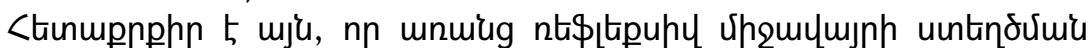

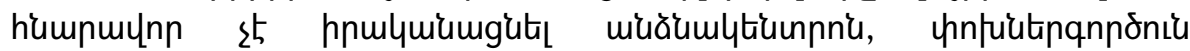

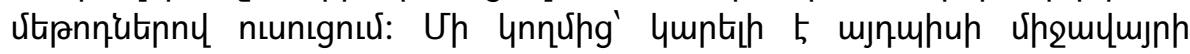

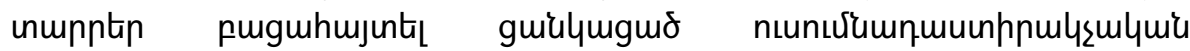

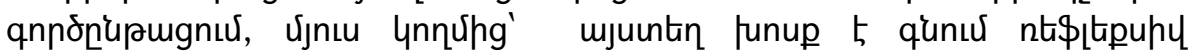

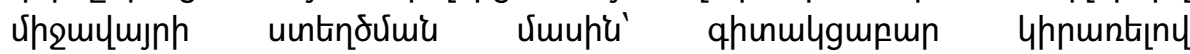

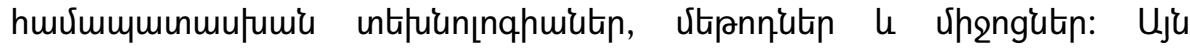

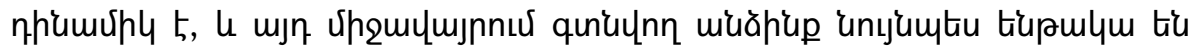

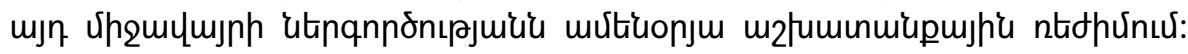

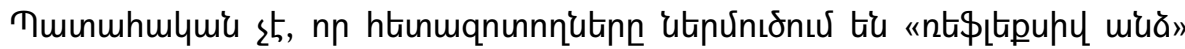

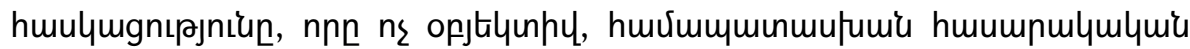

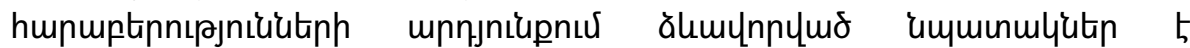

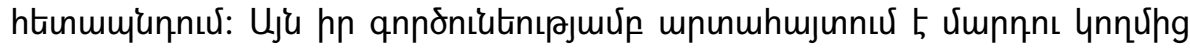

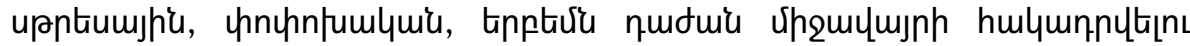

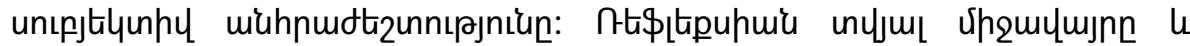

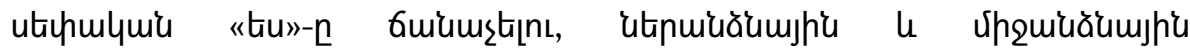

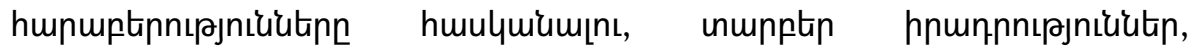

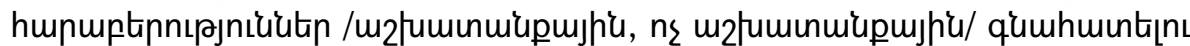

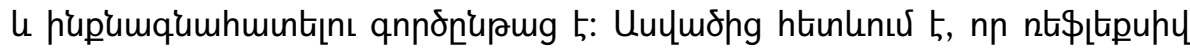

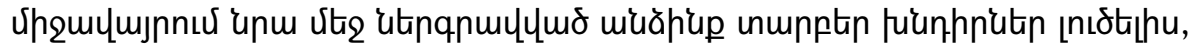

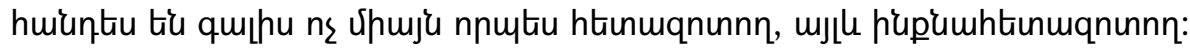

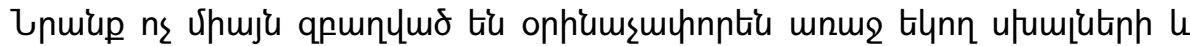

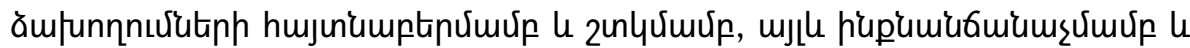

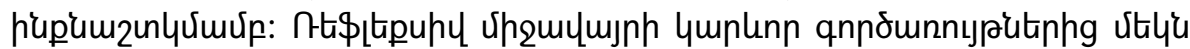

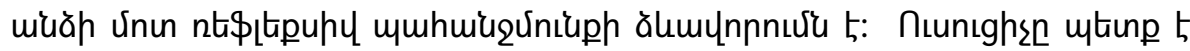

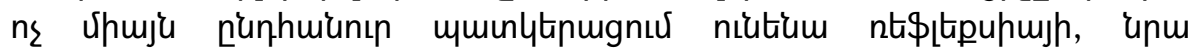

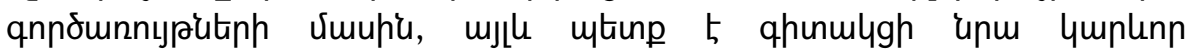

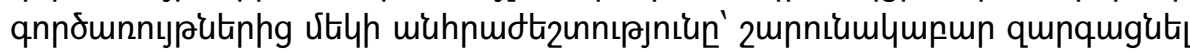




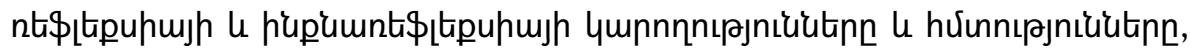
nt\$ltpuhy lnưultintiughuiu:

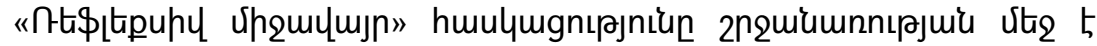

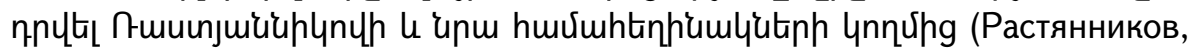

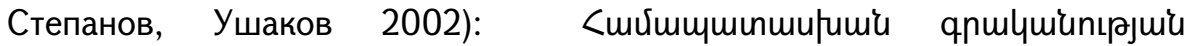

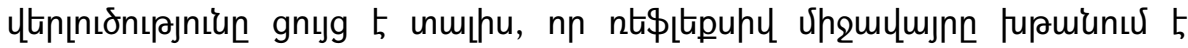

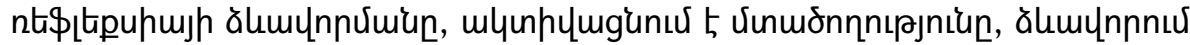

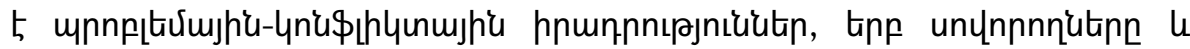

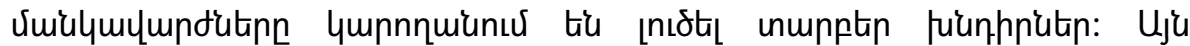

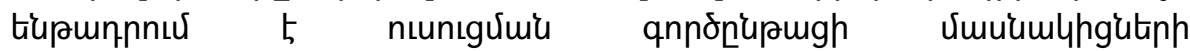

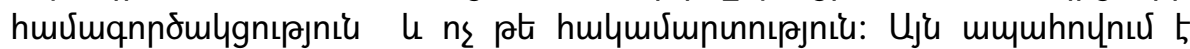

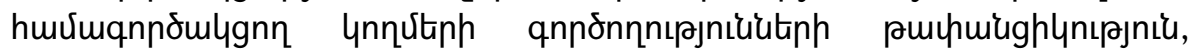

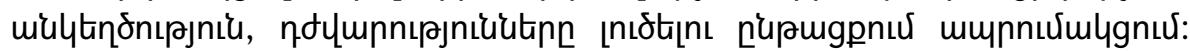

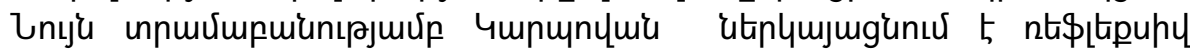

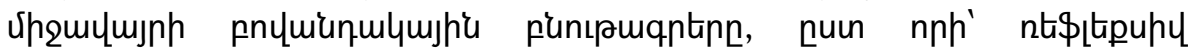

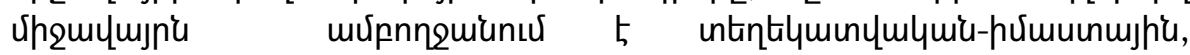

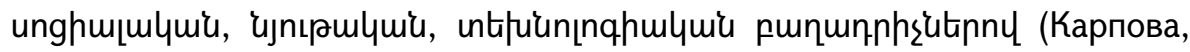
Шабалкова 2015: 8-10):

qдmumunltip 11.

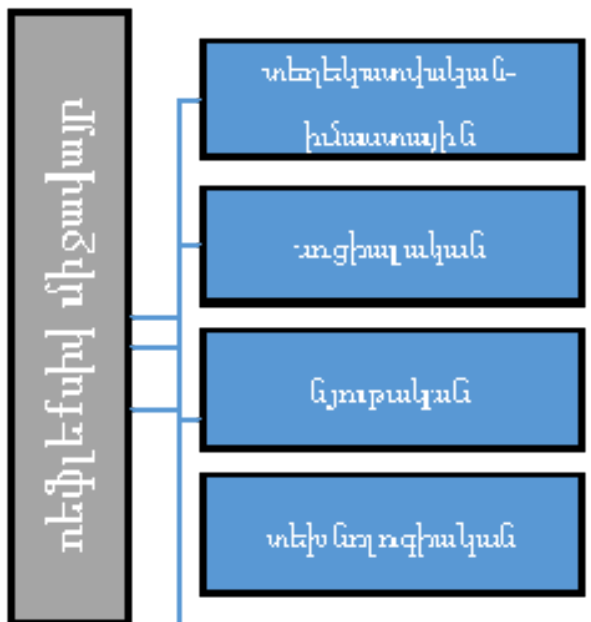

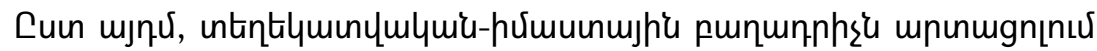

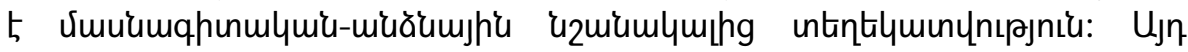

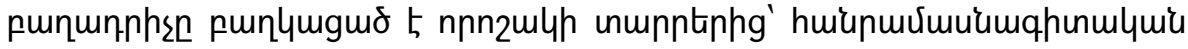

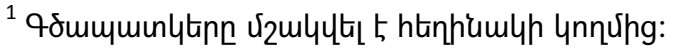




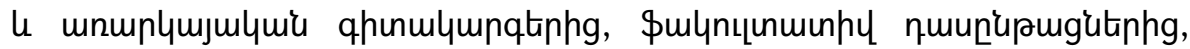

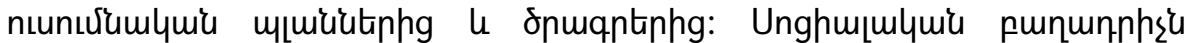

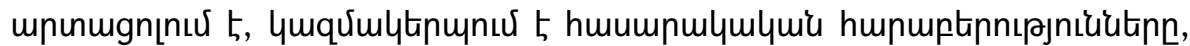

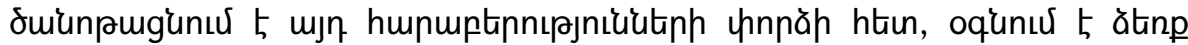

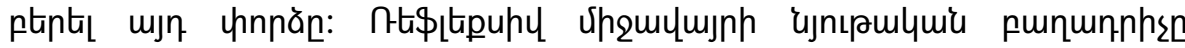

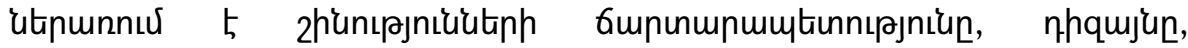

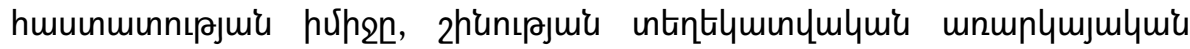

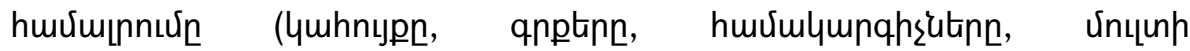
untumhurumlqunqtinn $u$ mృ (u):

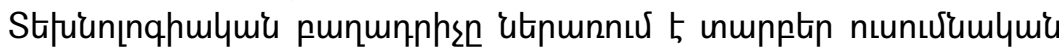

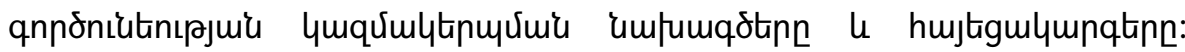

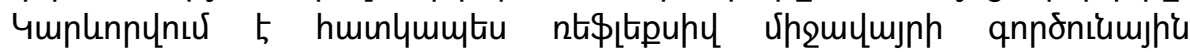

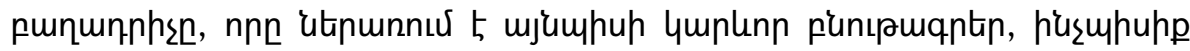
tiú'

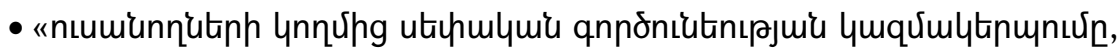

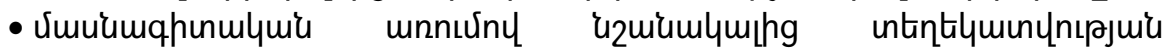

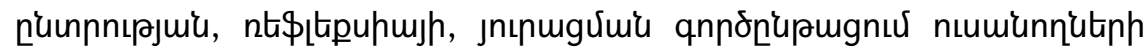

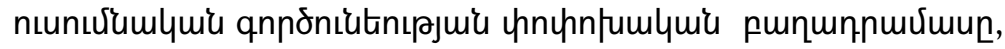

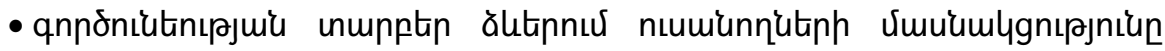

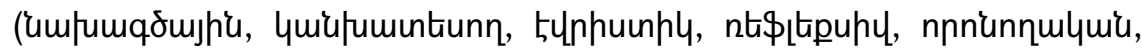

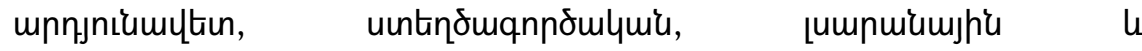
ununu[umpuizumjhi),

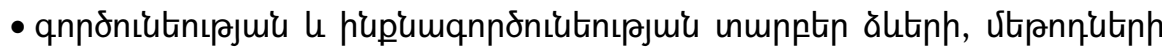
4hnunnuर» (Карпова, Шабалкова 2015: 8-10):

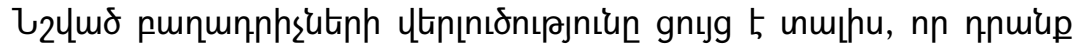

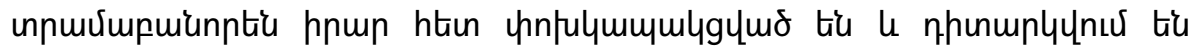

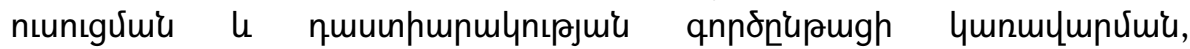

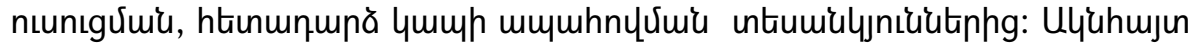

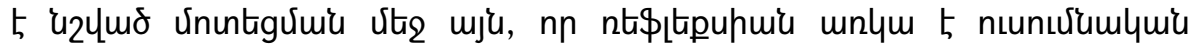

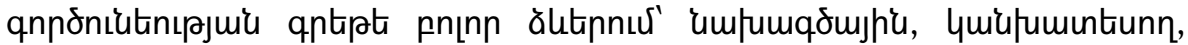

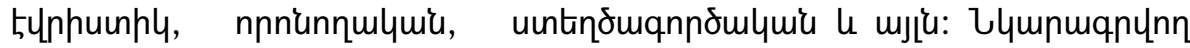

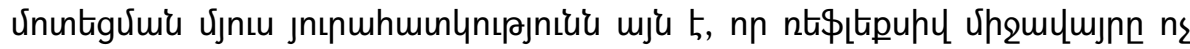

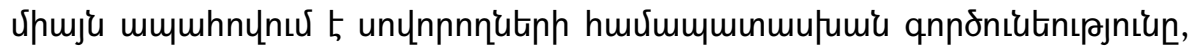

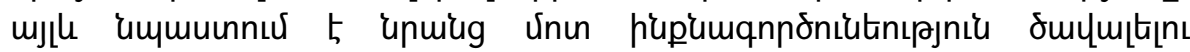

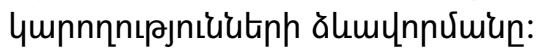

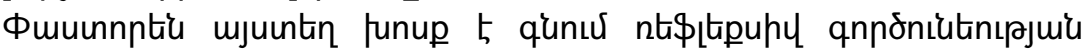

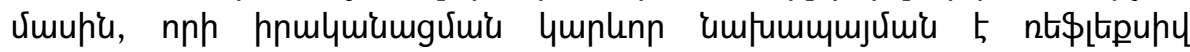

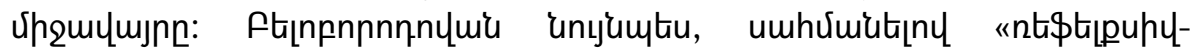

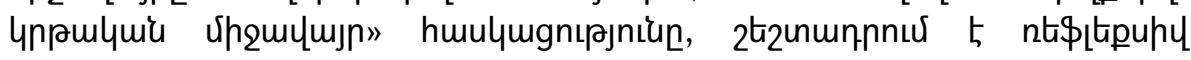




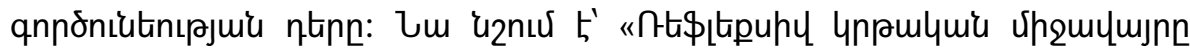

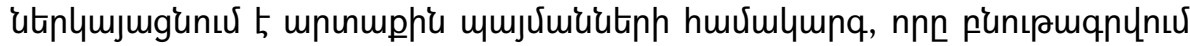

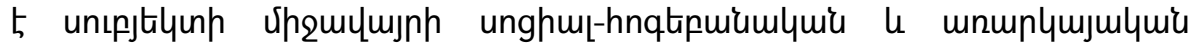

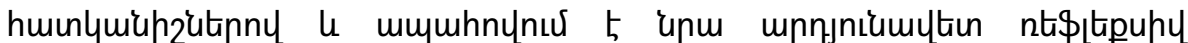

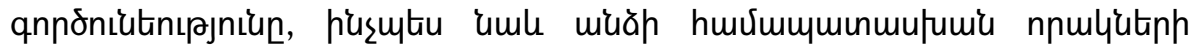

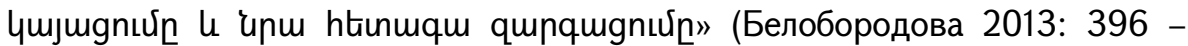

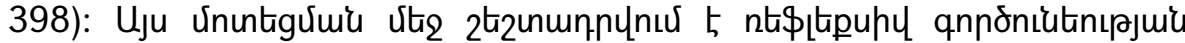

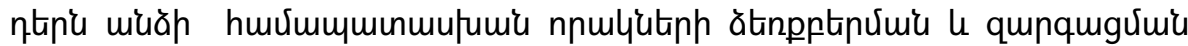

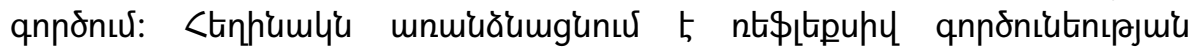

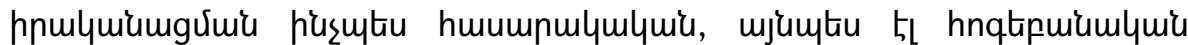

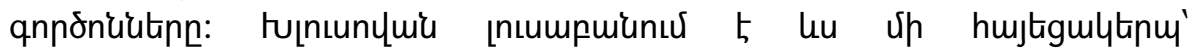

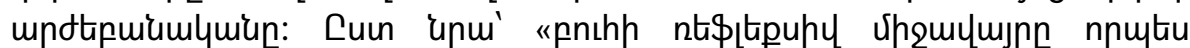

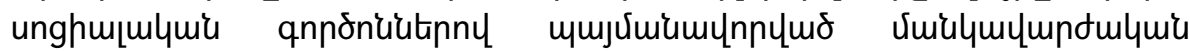

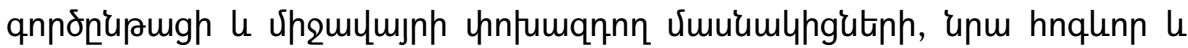

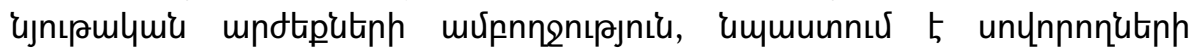

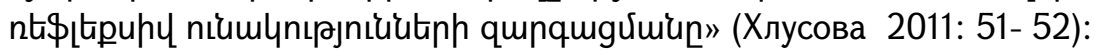

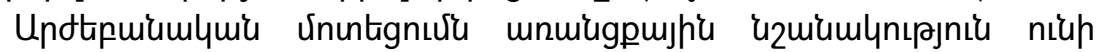

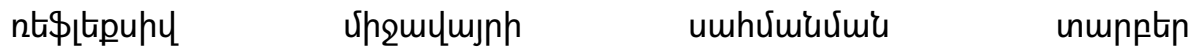

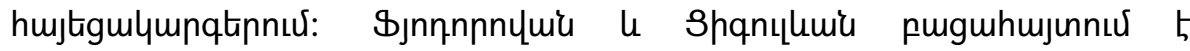

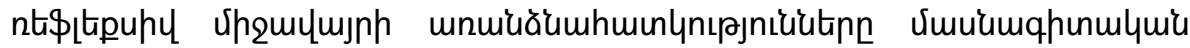

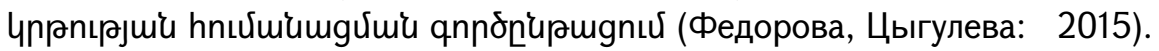

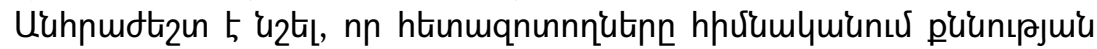

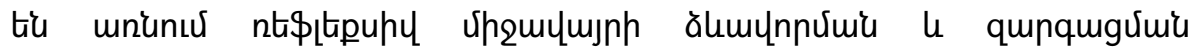

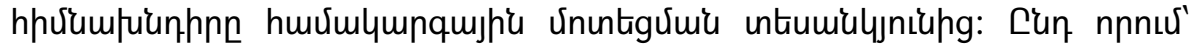

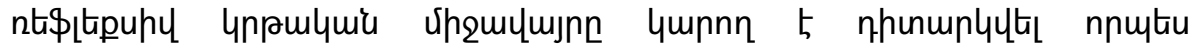

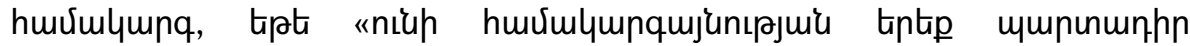

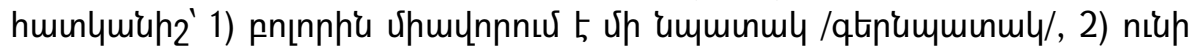

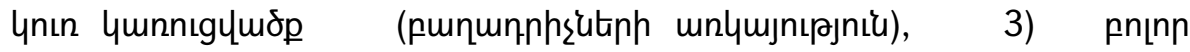

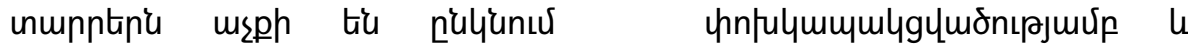

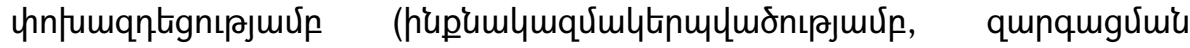

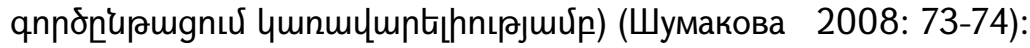

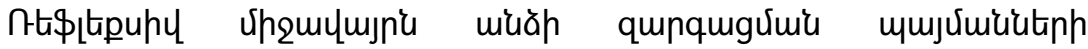

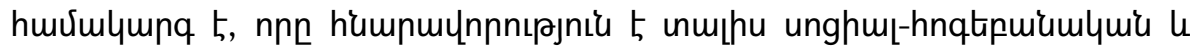

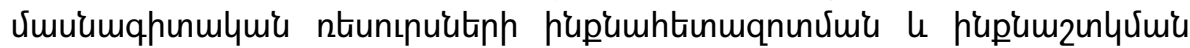

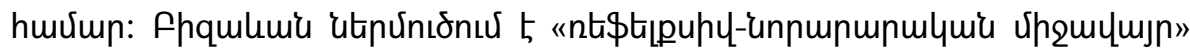

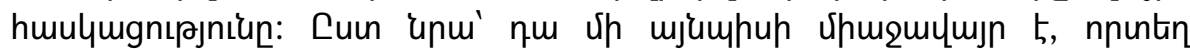

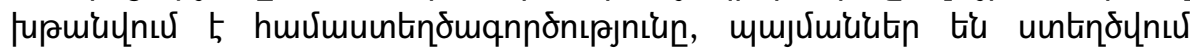

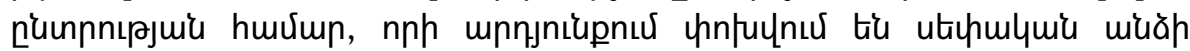

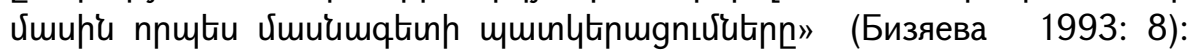




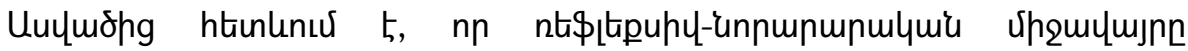

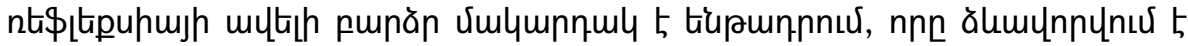

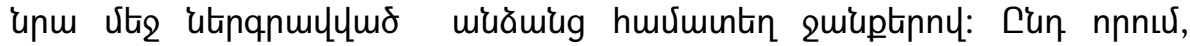

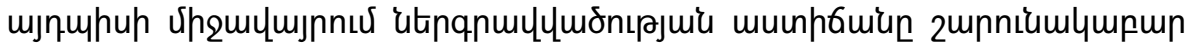

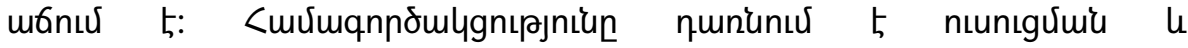

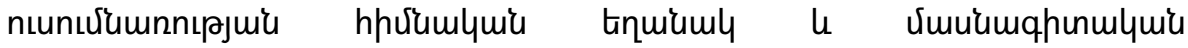

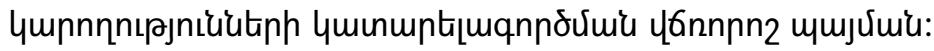

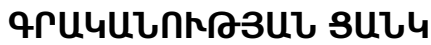

1. Аверина М. Н., Педагогические условия развития рефлексивных умений в процессе повышения квалификации учителей//Наука, образование, технологии. Преподаватель XXI век, 2011, N3, с.72-77.

2. Белобородова M.Е., Рефрлексивная образовательная среда и ее компоненты // Вектор науки Тольяттинского государственного университета, 2013, № 2 (24), с.396 - 398.

3. Бизяева А.А. Рефлексивные процессы в сознании и деятельности учителя: Автореферат дисс., канд. психол. наук. СПб., РГПУ им. А.И. Герцена, 1993, 20 с.

4. Карпова О. Л., Шабалкова Т.Н. Содержательные характеристики актуализации самообразовательной деятельности студентов вуза // Теория и практика фризической культуры, 2015. - № 5, с. 8 - 10.

5. Растянников А.В., Степанов С.Ю., Ушаков Д.В. Рефлексивное развитие компетентности в совместном творчестве, М., ПЕР СЭ, 2002, $320 \mathrm{c}$.

6. Федорова М.А., Цыгулева М.В. Рефлексивная среда как условие гуманитаризации профессионального образования (научный обзор) // Современные проблемы науки и образования. - 2015, №5, Дата обращения 15.03.2021

http://www.science-education.ru/ru/article/view?id=21852.

7. Хлусова А.А. Рерлексивная среда как компонент технологии формирования рефрлексивной компетентности студентов // Историческая и социально-образовательная мысль.2011, №3, с. 51-55.

8. Шумакова И.А. Понятие «рефрлексивная образовательная среда»в философии образования.Научные ведомости No 4 (44) 2008, с.73-74. 


\section{REFERENCES}

1. Averina M. N. Pedagogicheskie uslovija razvitija refleksivnyh umenij $v$ processe povyshenija kvalifikacii uchitelej//Nauka, obrazovanie, tehnologii. Prepodavatel' XXIvek. - 2011. - \#3. - S.72-77.

2. Beloborodova M.E. Refleksivnaja obrazovatel'naja sreda i ee komponenty // Vektor nauki Tol'jattinskogo gosudarstvennogo universiteta. - 2013. - № 2 (24). - S. 396 - 398.

3. Bizjaeva A.A. Refleksivnye processy $v$ soznanii $i$ dejatel'nosti uchitelja: Avtoreferat dis. ... kand. psihol. nauk. SPb.: RGPU im. A.I. Gercena, 1993. - $20 \mathrm{~s}$.

4. Karpova O. L., Shabalkova T.N. Soderzhatel'nye harakteristiki aktualizacii samoobrazovatel'noj dejatel'nosti studentov vuza // Teorija i praktika fizicheskoj kul'tury. -2015. - № 5. -S. 8-10.

5. Rastjannikov A.V., Stepanov S.Ju., Ushakov D.V. Refleksivnoe razvitie kompetentnosti v sovmestnom tvorchestve. - M.: PER SJe, 2002. - $320 \mathrm{~s}$.

6. Fedorova M.A., Cyguleva M.V. Refleksivnaja sreda kak uslovie gumanitarizacii professional'nogo obrazovanija (nauchnyj obzor) // Sovremennye problemy nauki i obrazovanija. - 2015.-№5. Data obrashhenija 15.03.2021 http://www.scienceeducation.ru/ru/article/view?id=21852.

7. Hlusova A.A. Refleksivnaja sreda kak komponent tehnologii formirovanija refleksivnoj kompetentnosti studentov // Istoricheskaja i social'noobrazovatel'naja mysl'. 2011. - № 3. - S. 51 -55.

8. Shumakova I.A. Ponjatie «refleksivnaja obrazovatel'naja sreda»v filosofii obrazovanija.Nauchnye vedomosti No 4 (44) 2008, s.73-74.

\section{НАРИНЕ МАТИНЯН - ПЕДАГОГИЧЕСКИЕ УСЛОВИЯ ФОРМИРОВАНИЯ РЕФЛЕКСИВНОЙ СРЕДЫ}

Ключевые слова: рефрлексия, саморефрлексия, эгочентричный, интерактивный, самопознание, самокоррекция, рефрлексивная потребность, педагогическое состояние, ресрлексивная среда, рефрлексивная личность

Анализ соответствующей литературы показал, что рефрлексивная среда является не только важным условием осуществления эфффективной образовательной работы, но и своеобразным показателем уровня учебновоспитательного процесса. Рефлексивная среда осуществляет разные функции: информационную, оценивающую, диагностическую и 
подразумевает сотрудничество участников процесса обучения, а также прозрачность действий, искренность, эмпатию в процессе преодоления трудностей. Выделяются в структуре рефлексивной среды информационно-смысловые, социальные, материальные и технологические компоненты. Принципиально важно то, что личностноориентированные, интерактивные методы возможно успешно применять только при наличии рефлексивной среды. С одной стороны, интерактивные технологии отражают содержание, динамику развития рефрлексивной среды, с другой стороны, рефлексивная среда способствует внедрению новых, эффеективных учебно-воспитательных методов.

\section{NARINE MATINYAN - PEDAGOGICAL CONDITIONS FOR THE FORMATION OF A REFLEXIVE ENVIRONMENT}

Keywords: reflection, self-reflection, self-centered, interactive, selfcognition, self-correction, reflexive need, pedagogical condition, reflexive environment, reflexive person

The analysis of the relevant literature shows that the reflexive environment is an important condition for the implementation of effective educational work, but it is also a kind of indicator of the level of the educational process. The reflexive environment performs different functions: informational, evaluating, diagnostic and implies cooperation of the participants in the learning process, as well as transparency of actions, sincerity, empathy in the process of overcoming difficulties. Informationsemantic, social, material and technological components are distinguished in the structure of the reflexive environment. It is fundamentally important that personality-oriented, interactive methods be successfully applied only in the presence of a reflexive environment. On the one hand, interactive technologies reflect the content, the dynamics of the development of the reflexive environment. On the other hand, the reflexive environment promotes the introduction of new, effective teaching and educational methods.

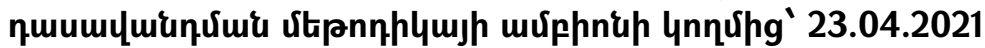

